\title{
The Effect of Socio-demographic Factors on the Utilization of Maternal Health Care Services in Uganda
}

\author{
Ishmael Kalule-Sabiti, Acheampong Yaw Amoateng and Mirriam Ngake \\ School of Research and Post-Graduate Studies \\ North-West University (Mafikeng Campus)
}

\begin{abstract}
The aim of this study was to investigate the effect of demographic and socio-economic factors on the utilization of maternal health care services using the 2006 Uganda Demographic Health Survey. Three measures of maternal health care services are examined, namely visits to antenatal clinic, tetanus toxoid injection and place of delivery. Using binary logistic regression model, we found that urban women are more likely than their rural counterparts to use antenatal care services, receive tetanus toxoid injection and deliver their babies in public health facilities. The same positive association was observed between a woman's educational attainment and visit to antenatal care clinic, place of delivery and tetanus toxoid injection. The policy implications of general socio-economic empowerment of women are discussed.
\end{abstract}

Keywords: Utilization; Maternal Health Care services; Clinic, Pregnancy; antenatal

\section{Résumé}

L'objectif de cette étude était d'étudier l'effet de facteurs démographiques et socio-économiques sur le Gebruik van maternale health care services met behulp van secundaire data van de 2006 Oeganda Demografische Health Survey. Trois mesures des services de soins de santé maternelle comme une variable de résultat C'est-à-dire de visites prénatales, l'anatoxine tétanique injection et lieu de livraison ont été examinés. Utilisez binary modèle de régression logistique, nous avons constaté que les femmes des zones urbaines sont plus susceptibles que leurs homologues des régions rurales à utiliser services de soins prénatals, recevoir de l'anatoxine tétanique injection et livrer leurs bébés dans les établissements de santé publique. La même association positive $a$ été observée entre une femme de scolarité et visite de soins prénatals Clinique, lieu de livraison et l'anatoxine tétanique injection. L'importance de la prestation de services dans le domaine critique général progrès socio-économique des femmes dans le domaine de l'utilisation des soins de santé ne saurait être trop soulignée.

Mots clé: Utilisation; Services de soins de santé maternelle; Clinique; La grossesse; Les soins prénatals

\section{Introduction}

Pregnancy-related complications are a leading cause of death amongst women in the reproductive age in the developing world. According to the United Nations (2005) more than half a million women in developing countries die each year during pregnancy or childbirth and twenty times that number suffer serious injury or disability. Some progress has been made in reducing maternal deaths in developing regions, but not in the countries where giving birth is most risky (United Nations 2005). Regionally, Africa has just $12 \%$ of the global population, but it accounts for half of all maternal deaths and half the deaths of children under five year of age. Nearly 4.7 million mothers, new-borns, and children die each year in sub-Saharan Africa: 265,000 mothers die due to complications of pregnancy and childbirth (Bryce \& Requero 2010; UNICEF 2009).

As far as Uganda is concerned, the country was expected to reduce its maternal mortality ratio to 131 per 100,000 births in 2015 in line with the Millennium Development Goals (MDGs) (United Nations 2005). However, according to a recent report, maternal mortality has increased to 438 per 100,000 births. Moreover, the expectation that all births would be attended by skilled health personnel by 2015 has similarly been elusive as only $59 \%$ of 
the births were attended by skilled personnel (Uganda Bureau of Statistics 20I I).

Measures of maternal deaths are critical as they reflect a woman's access to and use of essential health care services during pregnancy and childbirth, their general health and nutritional status, as well as their access to reproductive care services, including family planning (Mokomane and Khan 2009). However, there are factors that deter women, especially those living in rural areas, from using maternal health care services such as cultural barriers in seeking access, maltreatment by medical personnel, limited reproductive health knowledge, reliance on traditional medicine, malaria and the cost of transportation from their residence to the health facility.

\section{Literature Review}

Several studies have shown that socio-demographic factors affect the utilisation of maternal health care services (Celic \& Hotchkiss 2000; Mekonnen \& Mekonnen 2003; Woldemicael \& Tenkorang 2009). Below we review the empirical evidence of the selected socio-demographic factors that affect the utilisation of maternal health care services. Even though previous studies have observed that age influences maternal health care services in developing countries (Mengistu and James 1996), there is no consensus on the direction of influence. On the one hand, scholars such as Okutu (20II) argue that younger (aged less than 20years) and middle aged mothers (aged 20-34years) are more likely to seek pregnancy-related care services from skilled attendants compared to mothers aged 34 and above years in Uganda.

This is supported by studies in Nigeria which found that health seeking behaviour increases with age and decreases at older ages (see e.g. Nwosu et al. 20I2), a situation the authors attribute to gained experience among old mothers and limited pregnancies at such ages. Moreover, in Ethiopia, older women were found to be reluctant in seeking health care services but rather preferred to deliver at home with the assistance of traditional birth attendants (UNFPA 2008; Regassa 20II). On the other hand, and contrary to Okutu's (20I I) findings, Asiimwe (2010) found that in western Uganda young mothers' maternal health care utilisation is a function of affordability rather than age, while Heidi et al. (2006) found no significant differences between young and old mothers with regard to seeking antenatal and delivery health care services in Uganda.

Some studies have shown that women's education increases the use of maternal care services (e.g. Celik and Hotchkiss 2000; Gubhaju 2000). Educated women are more likely than uneducated women to use antenatal care, to use it early and frequently, and to use trained providers and medical institutions. This is exemplified by findings of the Ethiopia DHS 20II which indicates that 5 per cent of births to mothers with no education were attended by a health professional and delivered in a health facility compared with between 70 and 72 per cent of births to mothers with some secondary education (Central Statistical Agency and ICF Macro 20I I). It has also been found that education is positively associated with other aspects of maternal care. For example, in Nepal, one study found that women with more than primary level education were more likely to use antenatal care than those with no education (Gubhaju 2000), while in Turkey it was found that women with six or more years of schooling were more likely to use antenatal care than those with no education (Celik and Hotchkiss 2000).

In a study of the utilization of maternal health care services in Ethiopia, a statistically significant difference was found for the effect of education even after controlling for the effects of other variables (Dagne 2010). Furthermore, it was found that women with partners who had a secondary or higher education had two times higher odds of delivering with professional assistance when compared to those with partners having no education. In Uganda, in a study that used the 2006 and 201 I Demographic and Health Survey data to examine the socio-demographic factors that influence contraceptive use, the authors found that the likelihood of using contraception was associated with women's educational attainment. The more schooling a woman had, the more likely she was to report use of a modern contraceptive method. In each age group, over one-third of women with secondary or higher education, but far fewer women with no education, reported modern contraceptive use (Asiime, Ndugga and Mushomi 2013).

Similarly, Vallieres et al. (20/3) found a significant difference in skilled birth attendance between heads of households in Uganda with some primary education and heads of household with some 
secondary education or higher whereby those with secondary or higher education were significantly more likely to seek a skilled birth attendant. The difference in health centre delivery between heads of household with a primary education and heads of household with a secondary or higher education was also significant; those with secondary or higher education were significantly more likely to deliver in a health facility.

Education empowers women in terms of not only knowledge about the availability and benefits of maternal health services but also the autonomy to make independent decisions about their health. In view of this, we expect women who are educated to make more frequent use of maternal health care services compared to those who are not educated. These patterns are consistent with those observed with respect to other reproductive health services, such as contraceptive use.

Place of residence has been found to influence the utilization of maternal health care services. For example, in Ethiopia, rural women have been found to be generally less likely to give birth in a health facility compared to their urban counterparts (Mesfin Nigussie and Getnet 2004), and a similar situation was observed in Nigeria (Babalola and Fatusi 2009). Moreover, a study done in Ethiopia using the country's 2000 Demographic and Health Survey data, found that $27 \%$ of mothers who gave birth in the five years before the survey received antenatal care from health professionals and of this urban women showed higher use of antenatal care than their rural counterparts; $83 \%$ of women in Addis Ababa, the country's capital city, compared to $22 \%$ in the rural regions (Mekonnen and Mekonnen 2003).

In his study, Dagne $(2010)$ found that women living in rural areas had a $69 \%$ less odds of delivering by assistance from health professionals when compared to urban women. In a three-country study, Smith and Sulzbach (2008) observed that across all three countries, living in an urban area was associated with higher odds of delivering at a health facility; in Mali, living in an urban area (either Bla town or Sikasso) is positively associated with delivery at either a public or private health facility. Because of the relatively poor infrastructure like roads and clinics in rural areas in most African countries, we expect that the levels of use of maternal health care services among women will be generally lower in rural areas compared to those of women in urban areas.

Economic stability has been identified as important in influencing maternal health care service utilization behaviour of women. For example, a study in more than 50 countries showed that on average more than $80 \%$ of births were attended for the richest women compared with only $34 \%$ of the poorest women (Gill, Pande and Malhotra 2007). In Ethiopia, Dagne (2010) found a statistically significant association between household wealth and assistance during delivery with women in the rich and richest wealth groups more likely to have professional assistance during birth. In India, among women of medium and high standard of living, the odds of delivery in an institution were 1.4 times and 2.3 times respectively than those of women with a low standard of living (Ram and Singh 2006)

In their study in Uganda, Asiimwe, Ndugga and Mushomi (2013) found that in both 2006 and $201 \mathrm{I}$ surveys, modern contraceptive use was positively associated with level of household wealth. For age groups 15-24 and 25-34 years, use of modern contraceptive methods was highest among women from the richest households; wealth-related disparities in contraceptive use were greater among younger women.

In a three-country study of Ghana, Mali and Senegal in which the authors examined the relationship between Community-Based Health Insurance ( $\mathrm{CBHI})$, they found across all study areas that household SES was positively and, in some cases, significantly, associated with the use of prenatal care (Smith and Sulzbach 2008). Moreover, as was found with prenatal care, household SES was positively related to delivery at a health facility across all three study areas, but only significant for Ghana. Besides paying for the direct services offered by clinics, women also have to pay for indirect and related costs such as transportation and food. Because of these costs involved in the utilization of maternal health services, we expect wealth index to be positively associated with the utilization of such services in the present study.

Religion has been found to be associated with the use of maternal health care services. For example, in a study using the 2000 Ethiopian Demographic and Health Survey data, it was found that individuals professing Orthodox/Catholic, Muslim and Protestant faiths tended to use more maternal health services than those following traditional 
beliefs (Mekonnen and Mekonnen 2003). Corroborating the effect of religion in Ethiopia, Dagne (2010) found that women who followed traditional beliefs had a $50 \%$ lower chance of receiving antenatal care compared with those who followed Orthodox/Catholic faiths.

In their study of Ouagadougou, Burkina Faso, Soura, Pison, Senderowicz \& Rossier (2013) found a significant relationship between child vaccination rates and parents' religious affiliation. Specifically, they found that compared to children in Muslim families, those in Catholic families had less risk of being incompletely vaccinated after controlling for all relevant factors. Because of the historical ties of Christianity to Western cultures, Christians in most African societies tend to have Western, modernising outlook compared to their Muslim counterparts and those submitting to African traditional religions who tend to be traditional in outlook. Because of these cultural differences, we expect Christians to be frequent users of maternal health care services than both Muslims and Traditional African believers and other believers.

Birth order has been shown to influence the use of maternal care services in several studies. In Ethiopia and Rwanda, birth order of the child showed significant association with the use of antenatal care services and use of assistance during delivery; use of these maternal care services was shown to decrease with increase in birth order (Dagne, 20l0; ayaraman et al. 2008). Children are a constraint on time and money and therefore represent opportunity costs involved in this kind of transaction. We therefore expect women with more children to have lower levels of use of maternal health care services because of the constraints of time and money. Also, greater use of maternal health care services for first births may be attributed to higher risk of complications (e.g. Majoko et al. 2004).

With respect to marital status, there is a strong belief that women in unions are more likely to access maternal health care services during their first trimester compared to those who are not. This is because of the likelihood that married women are more likely to be supported by their spouses, and are more likely to have disposable income required to access maternal health services and are less likely to be autonomous (Ochako et al. 20l I). Through her work among adolescents in western Uganda, Asiimwe (2010), for example, has argued that the number of antenatal care visits is a function of marital status with the married being more likely to seek services compared to unmarried women. While her findings were consistent with what was observed in Ethiopia (Mekonnen et al. 2002), Lwelamira and Safan (20I2) found no effect for marital status in Tanzania.

As the above review of the empirical literature has shown, the literature is replete with examples of works that have been done to examine the utilization of maternal care services in sub-Saharan Africa. However, as is quite clear from the review, many of these studies are limited to looking at this issue in selected areas (districts, rural or urban) within selected countries of the African region. The main problem with the use of localized samples is that they are limited in their ability to generalize beyond the populations of such areas. A related problem about localized samples is that they tend to slow the progress in addressing the problem of access to maternal health care services in Africa because of their limited contribution to the existing knowledge base. It is against this backdrop of the limitations of existing studies on the utilization of maternal health care services that the present study is undertaken. The study seeks to understand the effect of demographic and socio-economic factors on maternal health care utilization in Uganda. The study departs from many of the existing studies on the utilization of maternal health care services in that it uses a national sample to examine the effect of age, place of residence, marital status, education, religion, birth order and wealth index on the utilization of maternal care services in Uganda by using the 2006 Uganda Demographic and Health Survey data.

\section{Data and Methods}

Data for the study were obtained from a probability sample of 9864 households selected for the 2006 UDHS survey. The sampling was done in in two stages. The first stage involved the selection of clusters from the list of samples, while in the second stage households were selected from each of the clusters. Data were collected from 8531 women aged 15-49 and 2503 men aged 15-59 (Uganda Bureau of Statistics and Macro International Inc. 2007). However, in this study, we excluded women who had not given birth as at the time of the survey; we focused on those women who gave birth in the last five years prior to the survey. Women who did not provide information on the antenatal clinic visit 
status, tetanus injection status and their place of delivery were also excluded from the analysis. Excluding this set of women from the original data set and treatment of missing values in some of the independent variables resulted in an effective sample size of 4946.

The data are analysed using the Statistical Package for Social Sciences. Univariate, bivariate and multivariate analyses are employed for the present study. Specifically, for the multivariate analysis, the logistic regression model is employed. This model requires the dependent variable to be measured at the nominal (Categorical) level. Since the log odds can be any number between minus and plus infinity, it can be modelled as a linear function of the predictor set and thus making the logistic regression model as follows:

$$
\begin{gathered}
\log (\pi)=\alpha+\beta 1 X 1+\beta 2 X 2+\ldots \ldots \ldots+\beta \mathrm{kXk} \\
1-\pi
\end{gathered}
$$

In the present study, the log odds of women utilising maternal health care services in Uganda are regressed on selected socio-demographic factors
(Park, 2009:6). The independent variables are represented by $\mathrm{X}_{1}, \mathrm{X}_{2}, \mathrm{X}_{3} \ldots \ldots \ldots \mathrm{X}_{\mathrm{k}}$. In this analysis, the predictors include age, type of place of residence, religion, marital status, birth order, educational level and wealth index.

\section{Results}

Table I shows the distribution of the sample characteristics. About $70 \%$ of the respondents are in the 20-34 age group, slightly less than a quarter are 35 years old or above, while only $7.4 \%$ are in the teen years of 15 to 19 years. The majority $(87.4 \%)$ of the women are resident in rural areas, while an equal number of women are Christian (87\%); only $2 \%$ belong to other religious groups. Eighty-four per cent of the women are married compared to only $4 \%$ who have never been married. In terms of educational attainment, the bulk of the women (61\%) have only primary education, while more than a fifth of the women (23\%) have no formal education; only $16 \%$ have secondary or more education. Finally, 24\% and $21 \%$ respectively of the women are in the poorest and poorer categories; $18 \%$ are in the middle wealth index while the richer and richest categories constitute $18 \%$ each.

Table I: Socio-demographic characteristics of the sample in the study

\section{Variable}

Age

$15-19$

20-34

$35+$

\section{Residence}

Urban

Rural

Muslim

Others

\section{Marital Status}

Never married

Married/living together

Widowed

Divorced/Not living together

\section{Birth order}

\section{Frequency}

Percent 
Education

None

Primary

Secondary+

Wealth Index

Poorest

Poorer

Middle

Richer

Richest

Total
1146

3033

767

1208

1048

907

881

902

4946
24.4

61.3

15.5

21.2

18.3

17.8

18.2

100.0

Table 2: Relationship between Maternal Care Services and Selected Socio-Demographic Variables in Uganda

\begin{tabular}{|c|c|c|c|c|c|c|c|c|c|c|}
\hline \multirow{3}{*}{$\begin{array}{c}\text { Variable } \\
\text { Residence: }\end{array}$} & \multicolumn{10}{|c|}{ Maternal Health Care Services } \\
\hline & \multicolumn{5}{|c|}{ Antenatal visit } & \multicolumn{3}{|c|}{ Place of Delivery } & \multicolumn{2}{|c|}{ Tetanus injection } \\
\hline & None & 1 & 2 & 3 & $4+$ & $\begin{array}{l}\text { Public } \\
\text { facility }\end{array}$ & $\begin{array}{l}\text { Private } \\
\text { facility }\end{array}$ & Home/other & $\begin{array}{c}\text { No } \\
\text { injection }\end{array}$ & Injection \\
\hline Urban & 2.1 & 4.8 & 7.2 & 23.4 & 62.6 & 59.0 & 25.1 & 15.8 & 13.9 & 86.1 \\
\hline Rural & 4.6 & 5.7 & 13.4 & 29.6 & 46.6 & 27.0 & 11.4 & 61.6 & 23.9 & 76.1 \\
\hline \multicolumn{11}{|l|}{ Age: } \\
\hline $15-19$ & 3.3 & 6.6 & 16.9 & 26.0 & 47.3 & 42.3 & 14.5 & 43.2 & 17.5 & 82.5 \\
\hline $20-34$ & 4.1 & 5.1 & 12.5 & 29.5 & 48.8 & 32.3 & 14.0 & 53.6 & 21.2 & 78.8 \\
\hline $35+$ & 5.3 & 6.6 & 11.5 & 27.9 & 48.6 & 23.4 & 9.9 & 66.7 & 28.6 & 71.4 \\
\hline \multicolumn{11}{|l|}{ Education: } \\
\hline None & 7.6 & 7.2 & 13.7 & 27.6 & 43.9 & 18.9 & 18.9 & 74.3 & 25.6 & 74.4 \\
\hline Primary & 3.6 & 5.6 & 13.6 & 30.4 & 46.7 & 30.6 & 30.6 & 57.6 & 23.5 & 76.5 \\
\hline Secondary+ & 2.2 & 2.9 & 7.0 & 24.5 & 63.4 & 50.7 & 50.7 & 21.3 & 14.9 & 85.1 \\
\hline \multicolumn{11}{|l|}{ Marital status: } \\
\hline Never married & 4.2 & 5.6 & 14.5 & 22.0 & 53.7 & 49.5 & 17.3 & 33.2 & 18.7 & 81.3 \\
\hline Married/LT & 4.3 & 5.7 & 12.8 & 28.6 & 48.6 & 29.9 & 13.0 & 57.1 & 22.9 & 77.1 \\
\hline Widowed & 3.9 & 5.2 & 12.3 & 36.4 & 42.2 & 24.0 & 13.6 & 62.3 & 22.7 & 77.3 \\
\hline Divorced & 4.8 & 4.3 & 10.0 & 32.0 & 48.9 & 34.8 & 12.5 & 52.7 & 22.0 & 78.0 \\
\hline \multicolumn{11}{|l|}{ Birth Order: } \\
\hline I & 2.4 & 4.6 & 13.1 & 23.8 & 56.1 & 48.8 & 15.6 & 35.6 & 15.9 & 84.1 \\
\hline $2-3$ & 4.3 & 5.8 & 12.0 & 28.9 & 49.0 & 33.2 & 15.2 & 51.6 & 17.2 & 82.8 \\
\hline $4-5$ & 3.9 & 12.7 & 12.7 & 30.9 & 47.5 & 28.0 & 13.9 & 58.1 & 23.2 & 76.8 \\
\hline $5+$ & 5.4 & 12.9 & 12.9 & 29.8 & 45.7 & 23.1 & 9.7 & 67.2 & 29.8 & 70.2 \\
\hline \multicolumn{11}{|l|}{ Religion: } \\
\hline Christian & 4.5 & 5.8 & 12.7 & 29.1 & 47.9 & 29.8 & 12.1 & 58.1 & 22.6 & 77.4 \\
\hline Muslim & 2.5 & 3.9 & 12.1 & 27.5 & 54.1 & 40.8 & 22.0 & 37.2 & 21.5 & 78.5 \\
\hline Other & 5.6 & 7.8 & 13.3 & 25.6 & 47.8 & 28.9 & 5.6 & 65.6 & 33.3 & 66.7 \\
\hline \multicolumn{11}{|l|}{ Wealth Index: } \\
\hline Poorest & 5.6 & 6.3 & 13.8 & 27.7 & 46.5 & 20.4 & 6.5 & 73.2 & 20.0 & 80.0 \\
\hline Poorer & 4.9 & 7.0 & 13.5 & 31.3 & 43.3 & 26.5 & 7.7 & 65.7 & 25.5 & 74.5 \\
\hline Middle & 3.9 & 5.2 & 14.8 & 32.9 & 43.3 & 27.1 & 10.5 & 62.4 & 26.2 & 73.8 \\
\hline Richer & 4.3 & 5.9 & 13.3 & 30.1 & 46.4 & 34.1 & 17.1 & 48.8 & 26.6 & 73.4 \\
\hline Richest & 2.2 & 3.1 & 7.2 & 22.3 & 65.2 & 51.6 & 27.1 & 21.4 & 15.4 & 84.6 \\
\hline
\end{tabular}

Table 2 shows the results of the bivariate analysis of the relationship between the background sociodemographic factors and the utilization of maternal health care services. Place of residence, education, birth order, wealth index were all strongly associated with all three measures of maternal health care services, while age, marital status and religion were either moderately or insignificantly associated with maternal health care services. For example, with regards to place of residence, majority of the urban women $(62.6 \%)$ had visited antenatal care service more than 4 times compared to only $46.6 \%$ of their rural counterparts. Moreover, while $84 \%$ of the urban residents delivered either at public or private health facilities, less than four out of ten (38\%) delivered at these health facilities; the bulk of the rural women (62\%) delivered at home. 
While the effect of age was almost non-existent with regards to antenatal care visit, it was strongly related to both tetanus toxoid injection and place of delivery. For these two measures of maternal health services, age was strongly and negatively associated with the utilization of such services. Like age, the effects of marital status and religious affiliation were observed for only place of delivery, whereby single, never married women were most likely to deliver their babies either at a public or private health facility than women who were married/living together, widowed and divorced. Sixty-seven percent of single, never married women delivered either at a public or private health facility compared to $47 \%, 43 \%$ and $38 \%$ of women who were divorced, married and widowed respectively. On the other hand, Muslim women were most likely to deliver either at a public or private health facility (63\%), while women who professed other religions were more likely to deliver at home (66\%), followed by Christians (58\%).

Finally, wealth index is strongly and positively associated with utilization of maternal health care services in that wealthy women are more likely to visit antenatal clinics more often, likely to receive tetanus toxoid injection and likely to deliver either at a public or private health facility. For example, $65 \%$ of wealthy women visited antenatal care clinic 4 or more times compared to $47 \%$ and $43 \%$ of poor and middle-income women respectively. Moreover, while over three-quarters of the rich women delivered either at a public or private health facility, only $27 \%$ and $38 \%$ respectively of poor and middleincome women delivered at these health facilities; the bulk of poor and middle income women deliver at home ( $73 \%$ and $62 \%$ respectively).

Table 3 presents the results of the binary logistic regression model which essentially confirm the bivariate analyses. Table 3 (Panel I) shows the effect of place of residence on the utilization of maternal health care services. Specifically, it shows that the odds of urban women visiting antenatal care clinics are I.40 times higher than the odds of rural women visiting antenatal care clinics. Moreover, the odds of urban women receiving tetanus toxoid injection are I.43 times higher than those of rural women. And, as shown in Table 3 (Panel III), like antenatal care visits and tetanus toxoid injection, urban residence is positively associated with place of delivery in Uganda. For instance, the odds of urban women giving birth in health facilities are almost three times
(2.99) higher than those of their rural counterparts, controlling for birth order, educational attainment and wealth index.

Even though contrary to expectation birth order does not make any difference in terms of the utilization of antenatal care visits, it is significantly associated with tetanus toxoid injection and place of delivery in Uganda as depicted by Table 3 (Panels II and III). On the whole, women with lower birth order are more likely than their counterparts with higher birth order to receive tetanus toxoid injection and also to give birth in a health facility. For example, the odds of women with first birth order receiving tetanus toxoid injection and giving birth in a health facility are 1.95 and 2.37 times higher than their counterparts with $6+$ birth order. And the odds of women with second and third birth orders receiving tetanus toxoid injection and giving birth in a health facility are 1.82 and 1.30 times higher than those with $6+$ birth order.

Formal education impacts positively on women's utilization of maternal care services in Uganda. For example, women without any formal education are less likely than their counterparts with primary education to visit antenatal care clinics and to deliver in a health facility. The odds of women with primary education visiting an antenatal clinic are 2.05 higher than those of women with no education, while the odds of women with primary school education delivering in a health facility are 1.47 times higher than those with no education. On the other hand, women with secondary or higher education are much more likely than their counterparts with no education to utilize maternal care services. For instance, the odds of women with secondary or higher education visiting an antenatal care clinic and receiving tetanus toxoid injection are 2.56 times higher than those of women with no education, while the odds of women with secondary or higher education delivering in a health facility are 3.69 times higher than those of their counterparts with primary education.

As expected, wealthy women are more likely than poor women to utilize maternal health services. The odds of richer women receiving tetanus toxoid injection are .7I times lower than the odds of the richest women receiving the injection, while the odds of women in lower categories of wealth delivering in a public or private health facility are much lower than those of women in the richest 
category of wealth $(58 \%, 39 \%, 35 \%$ and $29 \%$ respectively).

\section{Discussion}

As a region, sub-Saharan Africa is relatively lagging behind other regions of the world as far as 'inclusive' development is concerned. The region is yet to recognize the necessity for the development of a social policy framework which combines economic dynamism with an active role for government in the provision of basic social and other services at local and national levels. Notably, this failure of social policy has been manifested in the health sectors of most countries in the region with the prevalence of such challenges as high infant and child morbidity and mortality rates, high maternal mortality, high prevalence of HIV/AIDS, and low life expectancy with serious implications for socioeconomic development.

As far as maternal mortality is concerned, study after study has indicated that while generally in poorer or disadvantaged regions of the world it remains a major challenge, higher rates of utilization of maternal health care services helps in the reduction

Table 3: Logistic Regression Analysis of the Utilization of Maternal Health Care Services

\begin{tabular}{|c|c|c|c|c|c|c|}
\hline \multirow{4}{*}{ VARIABLE } & \multicolumn{2}{|c|}{ PANEL I } & \multicolumn{2}{|l|}{ PANEL 2} & \multicolumn{2}{|c|}{ PANEL 3} \\
\hline & \multicolumn{2}{|c|}{ Antenatal care visit } & \multicolumn{2}{|c|}{ Tetanus injection } & \multicolumn{2}{|c|}{ Place of delivery } \\
\hline & $\operatorname{Exp}(B)$ & $95 \%$ & $\operatorname{Exp}(B)$ & $95 \%$ & $\operatorname{Exp}(B)$ & $95 \%$ \\
\hline & & C.I(Exp(B)) & & C.I(Exp(B)) & & C.I(Exp(B) \\
\hline \multicolumn{7}{|l|}{ Age } \\
\hline $15-19$ & 0.740 & $0.328-1.673$ & 0.944 & $0.64 I-I .389$ & 1.020 & $0.726-1.433$ \\
\hline $20-34$ & 0.946 & $0.644-1.390$ & 1.020 & $0.845-1.231$ & 1.127 & $0.932-1.362$ \\
\hline $35+$ & 1.000 & Ref. Cat. & 1.000 & Ref. Cat. & 1.000 & Ref. Cat. \\
\hline \multicolumn{7}{|l|}{ Residence } \\
\hline Urban & 1.400 & $0.730-2.687$ & I.430**** & I.082-I.890 & 2.995* & $2.311-3.883$ \\
\hline Rural & 1.000 & Ref. Cat. & 1.000 & Ref. Cat. & 1.000 & Ref. Cat. \\
\hline \multicolumn{7}{|l|}{ Religion } \\
\hline Christian & & & 1.000 & Ref. Cat. & 1.000 & Ref. Cat. \\
\hline Muslim & & & 1.025 & $0.821-1.278$ & I.674* & $1.366-2.053$ \\
\hline Others & & & 0.647 & $0.410-1.019$ & 0.658 & $0.403-1.076$ \\
\hline \multicolumn{7}{|l|}{ Marital Status } \\
\hline Never married & & & & & 1.000 & Ref. Cat. \\
\hline MLT & & & & & 1.150 & $0.809-1.636$ \\
\hline Widowed & & & & & 1.220 & $0.740-2.013$ \\
\hline $\mathrm{D} / \mathrm{NLT}$ & & & & & 1.036 & $0.696-1.542$ \\
\hline \multicolumn{7}{|l|}{ Birth order } \\
\hline I & 1.870 & $0.975-3.583$ & $1.954 *$ & I.464-2.607 & $2.374 *$ & $|.830-3.08|$ \\
\hline $2-3$ & 1.093 & $0.726-1.645$ & $1.820 *$ & I.477-2.244 & I.298** & I.069-I.576 \\
\hline $4-5$ & 1.301 & $0.863-1.962$ & $1.315^{* *}$ & I.083-I.596 & 1.151 & $0.954-1.390$ \\
\hline $6+$ & 1.000 & Ref. Cat. & 1.000 & Ref. Cat. & 1.000 & Ref. Cat. \\
\hline \multicolumn{7}{|l|}{ Education } \\
\hline None & 1.000 & Ref. Cat. & 1.000 & Ref. Cat. & 1.000 & Ref. Cat. \\
\hline Primary & $2.054 *$ & $1.499-2.814$ & 1.089 & $0.919-1.290$ & $1.474 *$ & $1.250-1.738$ \\
\hline Secondary+ & $2.564 * *$ & I.398-4.703 & I. $450 * *$ & $1.098-1.916$ & $3.692 *$ & $2.863-4.762$ \\
\hline \multicolumn{7}{|l|}{ Wealth Index } \\
\hline Poorest & 0.733 & $0.396-1.356$ & 1.150 & $0.868-1.522$ & $0.290 *$ & $0.227-0.37 \mid$ \\
\hline Poorer & 0.718 & $0.389-1.325$ & 0.797 & $0.608-1.044$ & $0.353 *$ & $0.278-0.448$ \\
\hline Middle & 0.875 & $0.464-1.649$ & 0.781 & $0.595-1.024$ & $0.388 *$ & $0.305-0.493$ \\
\hline Richer & 0.701 & $0.383-I .284$ & $0.718 * * * *$ & $0.552-0.932$ & $0.575^{*}$ & $0.456-0.727$ \\
\hline Richest & 1.000 & Ref. Cat. & 1.000 & Ref. Cat. & 1.000 & Ref. Cat. \\
\hline
\end{tabular}

M/LT: Married/living together; D/NLT: Divorced/Not living together

of such deaths. As the findings of the present study have clearly shown, despite the efforts made by governments in the area of social policy since the early 2000s under the auspices of the African Union $(A U)$, the situation regarding the status of maternal health care in the region is still dire. In fact, apart from the case of tetanus toxoid injection where $77 \%$ of the women in the sample said they had received it, the rates for the remaining measures of maternal health care utilization are simply too low 
(48\% attended antenatal clinics, while $55 \%$ did not use health facilities for delivery).

Moreover, the findings of the study about the effects of factors like urban residence, education, and wealth index illustrate the elusiveness of the policy of 'inclusive' development in the region. Specifically, they show how some communities and sections of populations within countries have been excluded from having access to such basic social services as maternal health care services.

What this study has highlighted is the need for African governments to intensify efforts to engage with the social policy regime in the continent to ensure the socio-economic development of their peoples, especially, in the health sector, to arrest the situation where women and children die needlessly because of lack of access to quality health care. As already indicated, since the inception of the $A U$ in 2002 these efforts have been intensified following the adoption of several strategies with the aim of improving the health status of people in the African region. Among such strategies in the health sector are: The African Health Strategy: 2007-20I5, the Gaborone Declaration of 2005, the Alma Ata Declaration on Health for All through primary healthcare.

Moreover, following The Abuja Commitment of $15 \%$ of national budgets to health, several African countries have intensified efforts to develop strategies for health care financing including delivering on the community participation and mobilization for health care provision, extensive training for community health workers, and the establishment of district health committees; restructuring of government expenditure in the health sector in favour of preventive and community health care, paying particular attention to maternal and child health services, especially immunization; family planning programmes; public health education; nutrition; sanitation; and provision of safe drinking water; and ensuring an equitable access to health for everybody via adequate social protection mechanisms (AU, 2008). Making these commitments is indeed laudable within the context of where we have come from as a continent. What is needed now is the political will to deepen the actualization of such commitments.

\section{Conclusion}

The present study sought to examine the effect of selected socio-demographic factors on the utilization of maternal health care services by women in the 523 childbearing ages in Uganda, using the country's 2006 Demographic and Health Survey data. Three measures of maternal health care services, namely, visits to antenatal clinic, tetanus toxoid injection and place of delivery were examined to see how they are impacted by such socio-demographic factors as place of residence, educational attainment, birth order, religion, wealth index, marital status, and age. Using the binary logistic regression model, we found that variation in the utilization of maternal health care services among women of childbearing age in Uganda is associated with urban/rural residence, educational attainment, birth order and wealth index. In terms of residence, we found that women resident in urban areas are more likely than their rural counterparts to use antenatal care services, receive tetanus toxoid injection and deliver their babies in public health facilities. The same positive association is observed between a woman's educational attainment and visit to antenatal care clinic, place of delivery and tetanus toxoid injection.

Finally, wealth index is positively associated with both antenatal care and place of delivery in that women in the richest categories of wealth are more likely to have the injection and deliver their babies at health facilities than their counterparts in the poor and poorest categories of wealth. The fact that there is invariance in visit to antenatal clinics with respect to birth order and wealth index is perhaps a reflection of the strides that are being made in terms of the expansion of this health facility to the population in the country. In conclusion, this study has underscored the critical importance of the relationship between socioeconomic development and positive health outcomes as measured by the utilization of maternal health care services.

\section{References}

Asiimwe, J.B., Ndugga, P, and Mushomi, J. 2013. Socio-demographic factors associated with contraceptive use among young women in comparison with older women in Uganda. ICF International, Calverton, Maryland, USA. DHS Working Paper No. 95.

Asiimwe, K.J. 20I0. Utilization of antenatal services among adolescents in western Uganda, 2007. Available

from:http://uaps2007.princeton.edu/download.as px [Access date: 2.12.20I3]. 
Abor, P.A., Abekah-Nkrumah, G., Sakyi, K. Adjasi, C.K.D, and Abor, J. $20 \mathrm{II}$.

The socio-economic determinants of maternal health care utilisation in Ghana, International Journal of Socio-economic, 37 (7): 628-648.

Atuyambe. L., Mirembe, F., Tumwesigye, N.M., Annika, J. Kirumira, E. and Faxelid, E. 2008. Adolescent and adult first time mothers' health seeking practices during pregnancy and early motherhood in Wakiso district, central Uganda. Reproductive Health 2008, 5: I3,http://www.reproductive-healthjournal.com/content/5/I/I3.

$A U$ 2008. First Session of the AU Conference of Ministers in charge of

Social Development, Windhoek, Namibia 27 - 31 October 2008.

Babalola, S. and Fatusi, A. 2009. Determinants of use of maternal health services in

Nigeria: Looking beyond individual and household factors. BMC Pregnancy Childbirth, 9: 43.

Central Statistical Agency and ICF Macro 20II. Ethiopia Demographic and Health

Survey Calverton, Maryland, USA, ICF Macro.

Celik, Y. and Hotchkiss, D.R. 2000. The Socioeconomic determinants of maternal health care utilisation in Turkey. Social Science \& Medicine,50(I2): I797-806.

Chakraborty, N., Islam, M.A., Chowdhury, R.I., Bari, W. and

Akhter, H.H. 2003, "Determinants of the use of maternal health services in rural Bangladesh", Health Promotion International, 18 (4): 327-37.

Dagne, E. 2010. Role of socio-demographic factors on the utilization of maternal health care services in Ethiopia. Department of Public Health, Umea University, Ethiopia.

Gage, A.J. 2007. Barriers to the utilization of maternal health care in rural Mali,

Social Science \& Medicine, 65 (8): 1666-82.

Gill, K, Pande, R. \& Malhotra, A. 2007. Women deliver for development. Lancet 13 :

370 (9595): I 347-57.

Heidi W. R., Emelita L. Wong and Heidi Tucker. 2006. Adolescents' Use of Maternal and Child Health Services in Developing Countries. International Family Planning Perspectives, $32(1): 6-16$

Jayaraman, A, Chandrasekhar, $s$ and Gebreselassie, T. 2008. Factors Affecting
Maternal Health Care Seeking Behavior in Rwanda. Macro Internal Inc.

Kistiana, S. 2009. Socio-economic and demographic determinants of maternal health care utilization in Indonesia, Adelaide: The Flinders University of South Australia.

Lwelamira.J. and Safari.J. 2012. Choice of Place for Childbirth: Prevalence and Determinants of Health Facility Delivery Among Women in Bahi District, Central Tanzania.

Asian Journal of Medical Sciences, 4(3): I05-I I 2.

Majoko FM, Nyström L, Munjanja SP, Mason E, Lindmark G.2004. Relation of parity to pregnancy outcome in a rural community in Zimbabwe. African Journal of Reproductive Health. 8(3): 198206.

Mekonnen, Y. \& Mekonnen, A. 2003. Factors influencing the use of maternal healthcare services in Ethiopia, Journal of health, population \& nutrition, 2I(4) :374-382.

Mekonnen, Yared, and Asnaketch Mekonnen. 2002. Utilization of Maternal Health

Care Services in Ethiopia. Calverton, Maryland, USA: ORC Macro.

Mengistu, M. and J. James, 1996. Determinants of antenatal care utilization in Arsi Zone,

Central Ethiopia. Ethiopia Journal of Health and Development, 3: 17I-I78.

Mokomane, Z. and Khan, N. (2009) towards a I0year review of the population policy implementation in South Africa (1998-2008): Sexual and reproductive health and rights, South Africa: department of social development.

Mesfin Nigussie, DHM and getnet, M. 2004. Assessment of safe delivery service utilization among women of childbearing age in north Gondar Zone, North west Ethiopia. Ethiopia Journal of Health Development, 18(3).

Mustafizur Rahman,K.M. 2009. Determinants of Maternal Health Care Utilization in

Bangladesh. Research Journal of Applied Sceinces, Vol.4 Issue 3.

Nwosu.O.E, Urama. E.N, and Uruakpa, C. 2012. Determinants of Antenatal Care

Services Utilisation in Nigeria. Developing Country Studies, 2, No.6. www.iiste.org.

Ochako,R., Fotso,C.J, Ikamari,L. and Khasakhala, A. 201I. Utilization of maternal health services among young women in Kenya: Insights from the Kenya Demographic and Health Survey, 2003. BMC Pregnancy and Childbirth, , II:I. 
Okutu, D. 20II. Access to and utilization of antenatal care services in Uganda. uaps20 I I.princeton.edu/papers/ I 10707.

Ram, F and Singh, A. 2006. Is Antenatal Care Effective in Improving

Maternal Health in Rural Uttar Pradesh? Evidence from a District Level Household

Survey. Journal of Biosocial Science, 38(04): 433 448.

Regassa.N. 20II Antenatal and postnatal care service utilization in southern Ethiopia: a population-based study. African Health Sciences, I I; 3; 390-397.

Smith, KV and Sulzback, S 2008. Community-based health insurance and access to maternal health services: Evidence from three West African countries, Social Science \& Medicine, 66(12): 2460-2473.

Soura, A., Pison, G., Senderowicz, L., \& Rossier, C. 2013. Religious differences in child vaccination rates in urban Africa: Comparison of population surveillance data from Ouagadougou, Burkina Faso. African Population Studies, 27, No.2: 174187.

Uganda Bureau of Statistics. 2011. Uganda Demographic and Health Survey,
201 I: Preliminary Reports. Kampala, Uganda.

Umurungi, Y.S. 2010. Determinants of the utilisation of delivery services by pregnant women in Rwanda. Johannesburg: University of the Witwatersrand. (Dissertation - M.Sc.)

UNICEF 2009 State of the World's Children 2010. New York: UNICEF.

UNFPA 2008. Maternal Health Care Seeking Behaviour in Ethiopia: In-depth Analysis of the Ethiopian Demographic and Health Survey 2005.

United Nation, 2005, The Millennium Development Goals Report. New York

Vallieres, F., Hansen, A., McAuliffe, E., Cassidy, E.L., Owora, P., Kappler, S, and Gathuru, E. 2013. Head of household education level as a factor influencing whether delivery takes place in the presence of a skilled birth attendant in Busia, Uganda: a cross-sectional household study. BMC Pregnancy Childbirth, 13:48. doi: 10.1 186/147I2393-13-48.

Woldemicael, G. and Tenkorang, E.Y. 2009. Women's Autonomy and Maternal

Health-Seeking Behavior in Ethiopia. Maternal Child Health Journal. 